\title{
Choice between Alternative Routes to Go Public: \\ Backdoor Listing versus IPO
}

\section{Introduction}

Going public is the dream of many private companies. It represents a major milestone in the development of a firm. The listing status brings a lot of advantages to a firm. Some of these advantages include (1) access to capital markets and lower cost of capital; (2) enhanced company reputation and profile; (3) providing liquidity for owners to cash out; and (4) use of stock to pay for acquisitions, among others. However, going public is also a costly process. The out-of-pocket costs for an IPO typically involve fees paid for investment banks, accountants, auditors, lawyers, other experts, underwriters and brokers. The IPO firm will also have to pay for the printing of a prospectus and listing fees and other compliance costs. Other hidden costs entail underpricing, more stringent disclosure and regulatory requirements and the time spent by senior management in preparing the company for public listing.

Traditionally, going public via an IPO has been the predominant path for a private firm to obtain a listing status on a stock exchange. However, alternative routes for going public are also available. These include reverse takeover (RTO) or reverse merger (RM) and sell-out to a publicly-listed firm. The two alternatives are similar in the sense that both involve a publiclylisted company taking over a privately-owned firm. The major difference between the two lies in the ultimate control of the combined entity. In RTOs (or RMs), the private firm shareholders will have control whereas in the case of sell-outs, the public firm shareholders will still retain control. Because of the unique features of the RTO (or RM) transactions, going public through this path is commonly known as backdoor listing (hereafter BDL).

BDL deals are complex inter-corporate transactions by which unlisted private-held firms achieve a listing status through the corporate shell of publicly-listed companies. A BDL transaction is normally structured as a takeover of the private firm by the public company but in essence, the vendors of the private firm obtain control of the enlarged public shell (a 
reverse takeover) at the conclusion of the event. From the public firms' point of view, BDLs represent major corporate restructurings which typically involve a change of name, business activities, board of directors and management. From the private firms' perspective, BDLs can be seen as an alternative route for going public.

Backdoor listings occur in numerous stock exchanges and bourses around the globe. They are, in particular, popular in Australia as there has been no shortage in the supply of listed shell companies on the Australian Stock Exchange (ASX). The ASX has been dominated by the mining sector, with a large number of junior exploration companies listed. Given the riskiness of their endeavours and the cyclical nature of the mining sector, it is not unusual to witness a fair proportion of these firms facing financial distress when their funding dries up. These distressed firms serve as ideal candidates for being targeted as a shell for backdoor listing. Despite their prevalence, BDLs are heavily under-researched in the academic literature.

Backdoor listing has often been touted as a cheaper, easier and faster way to go public. However, empirical evidence to support such claims is sparse and, at best, anecdotal, depending on the regulatory regime in place. Whether backdoor listing in fact offers the benefits as commonly believed is an empirical question. One of the objectives of this paper is to provide empirical evidence to address that question. Another research question that will be dealt with is how private firms choose between the frontdoor (IPO) and backdoor path when they decide to go public.

The remainder of the paper is organised as follows. Section 2 reviews related prior literature on going public using alternative routes. Section 3 explains the data, sample and research design. Section 4 presents empirical results from both univariate and multivariate tests. Section 5 outlines results of robustness tests. Section 6 concludes the paper with a discussion and summary of findings. 


\section{Prior literature}

There have been a few recent studies in the literature examining the decision of firms to go public through alternative routes. Most of these studies are based on the evidence from the U.S. and Canadian markets. In general, RTO or RM firms are found to be smaller, younger and less profitable than their IPO counterparts. They also tend to have lower balance sheet liquidity and higher leverage (Gleason et al. 2006). RM firms tend to exhibit higher information asymmetry as a result of no prospectus requirement (Floros 2008; Carpentier et al 2009). They also have a lower tendency for insider shareholders to cash out and rely heavily on PIPE (private investments in public equity) investors for financing (Floros 2008).

Sjostrom (2008) argues that RMs and IPOs (in the U.S.) are not directly comparable as the two primary benefits of going public, viz., capital raising and liquidity, are largely absent for the RM firms. However, as evidence from section 4 below shows, Australian BDL firms are unique in that disclosure by way of prospectus and concurrent capital raisings are present in the vast majority of the cases, accounting for close to 80 percent of the sample. Thus Australian BDL firms are closer substitutes for IPOs than their U.S. or Canadian counterparts. The Australian setting would therefore provide a unique setting to examine the motivations of private firms in choosing the path for going public.

Besides RTOs, prior studies have analysed outright sell-out to a public firm as an alternative to going public through a direct IPO. Brau, Francis and Kohers (2003), for example, in comparing the alternatives of sell-outs versus IPOs, find that the IPO route is preferred by firms that are operating in highly concentrated markets, have higher level of insider ownership and assets but lower level of leverage and liquidity. IPOs are more likely in time periods corresponding to higher 3-month T-bill rates. In a related setting, Poulsen and Stegemoller (2006) find that private firms taking the IPO path tend to have higher pretransaction insider ownership and higher growth, with more investments and R\&D expenditures than firms choosing to do an outright sell-out to a public firm. To a certain extent, sell-outs are similar to RTOs (or BDLs) in the sense that both involve the acquisition 
of the private firm by a public firm. Nevertheless, the distinguishing feature of the two is that in sell-outs, even though the private firm vendors may end up holding blocks of shares in the merged entity, no change of control takes place. In other words, the shareholders of the public firm still control the enlarged entity after the acquisition.

Listing by introduction is another alternative path to going public that has been studied in the literature. By this process, private firms obtain their exchange listing status in exactly the same way as in IPOs but without the concurrent offering of any primary or secondary shares. Derrien and Kecskes (2007) examine the motivation for private firms to undertake a new listing by introduction, to be followed by an equity issue in the aftermarket. They argue that the trading created in the aftermarket helps reduce the valuation uncertainty of these firms, which in turn would lower the degree of underpricing when shares are offered in the second stage. Using a sample of hand-collected firms listed by introduction in the U.K., they find that these firms have initial returns of 10 to 30 percent lower than for comparable IPOs. There is also evidence that these firms engaged in market timing, both when they list and when they issue shares subsequently. To the extent that $\mathrm{BDL}$ transactions represent an alternative for the backdoored firm to gain an exchange listing status plus an option to defer issuing equity till a later day, they resemble the two-stage strategy of listing by introduction.

\section{Data and method}

\subsection{BDL sample}

Backdoor listing is a loosely-defined term that generally refers to a sequence of structured inter-company events by which a private firm achieves a listing status by undertaking a reverse takeover of a publicly-listed firm and using the corporate shell of the latter as a vehicle to go public. In Australia, reverse takeover transactions are normally structured as an acquisition by the public firm of all the shares in the private firm, so that the latter becomes a wholly-owned subsidiary of the former. However, the deal can also be 
structured as an acquisition of assets and business operations from the private firm vendors. The public firm pays for the acquisition by issuing a large quantity of new shares with voting rights in the company to the private firm vendors. The consideration shares may be supplemented by other forms of consideration, which may include cash, stock options, convertible notes and earn-outs (e.g., performance shares). At the conclusion of the reverse takeover transaction, the private firm vendors obtain effective control of the combined publicprivate entity. The private firm becomes part of an enlarged group, which is publicly-listed. In fact, the private firm business and assets will become the dominant focus of the merged entity since the public firm is essentially a corporate shell with no or minimal operations.

From the above discussion, it is evident that change of control is the critical aspect of a reverse takeover transaction. Without a change of control, the transaction would be just like a normal (forward) acquisition. Jensen and Ruback (1983) define corporate control as "the rights to determine the management of corporate resources". In other words, control can be regarded as the ability to set the future strategic direction of a company or change the way the company's assets are deployed. The change of control in a company can generally be effected through the following means: (i) ownership control—controls more than 50 percent of the voting shares, (ii) board control—controls more than half of the seats on the board of directors, and (iii) management control—controls or occupies the position of CEO or managing director. For publicly-listed companies, because of the dispersion of ownership, a majority shareholding (i.e., greater than 50 percent) may not be necessary for gaining effective control. In fact, a much lower threshold (20 percent) of ownership has been set as triggering the takeovers provisions in the Corporations Act.

In this study, change of control is operationalised as follows. If vendors of the private firm collectively control 50 percent or more of the voting rights of the public shell company through share ownership, a change of control is deemed to have occurred. Alternatively, if the 50 percent shareholding threshold is not reached, then a change of control is said to have occurred if the private firm vendors (i) collectively become the largest blockholder of shares 
in the public shell company, and (ii) either control more than half of the seats on the board of directors or occupy the position of CEO or managing director.

Since information on backdoor listings on the ASX is not readily available, these transactions have to be manually identified from various sources. Though no official definition of backdoor listing or reverse takeover exists in Australia, the media has been using these terms to report news or cover stories of corporate transactions of a similar vein. Therefore media search serves as the primary source of information for backdoor listing transactions for this study. The following steps were followed to identify a preliminary sample of BDL cases reported in the news media through Factiva.

1. A search of the Factiva database resulted in 1,604 media articles that contain the keywords (1) 'ASX' and (2) 'backdoor listing' or 'reverse takeover' or 'reverse merger' or 'change of activities', for the years $1992-2007^{1}$.

2. Through careful reading of the media articles (to eliminate irrelevant and duplicate cases), a sample of 296 potential BDL cases was identified. These cases are potential BDL deals only as there is no formal definition of what a backdoor listing or reverse takeover transaction is in Australia and the media has used this term in a fairly loose manner. Thus more in-depth research into the specific details of the deal structure is necessary to ascertain whether these preliminary transactions would meet the operational definition of what a BDL transaction is.

3. To this end, a history of name changes, including former names and date of change, for each of the potential firms was then reconstructed, from information available on both DatAnalysis (available through Aspect/Huntley) and www.delisted.com.au. The date of name change is particularly useful as the public firm typically changed its

\footnotetext{
${ }^{1}$ Due to various limitations, both the availability and reliability of the archival data tend to decline the further back in time it goes. Thus a sampling period from January 1992 to December 2007 was chosen to capture all BDL transactions which were completed within this 16-year time period. 1992 was the year when the Second Board Markets in all states were closed and witnessed a flurry of companies in those markets transferred their listing to the ASX. As many of these firms were smaller and weaker firms, they served potentially as prime targets for backdoor listings. Thus 1992 is a good starting point for the current study. The end of 2007 is the latest time feasible when the data collection work is conducted.
} 
name after a BDL transaction to better reflect a break from the past and the identity of the backdoor asset. Thus the date of name change provides a rough guide to the timing of the BDL transaction.

4. Using the Signal G platform (available through Aspect Financial), contents of the corporate announcements and disclosures made by each of the potential firms were manually scanned to look for evidence of BDL transactions.

5. Once a potential case was confirmed as falling under the operational definition of a BDL transaction, all relevant corporate announcements and documents, including proposed acquisition, suspension of trading, notice of general meeting, information memorandum, independent expert's report, results of general meeting, prospectus, pre-quotation disclosure, re-instatement to official list, etc., were downloaded and put into a folder.

6. The steps in (4) and (5) above were repeated for all 296 potential cases.

7. At the end of the process, a total of 183 cases meeting the operational definition of a BDL transaction were identified.

Towards a later stage of the data collection process, a second source of backdoor listing cases became available through the Zephyr database on mergers and acquisitions, made available by Bureau van Dijk. A search through Zephyr provided a list of 46 deals that are classified under the deal sub-type of reverse takeovers for ASX-listed firms over the period $1999-2007^{2}$. Further research into these firms using detailed company announcements resulted in 17 additional cases that meet the definition of BDL transactions.

All together, the final sample consists of 200 backdoor listing cases spanning the period from January 1992 to December 2007. These 200 cases involved 173 ASX-listed entities, of which 148 firms had one BDL transaction, 23 firms had two BDL transactions and two firms had three BDL transactions over the sampling period. Table 1 summarises the sampling procedure involved.

\footnotetext{
${ }^{2}$ The Zephyr database on reverse takeovers for ASX-listed firms only begins in 1999 and the coverage is relatively limited.
} 


\subsection{Matching IPO sample}

To examine the issue of why private firms would go public through the backdoor as opposed to the front-door, a control sample of IPO firms is needed. It is conceivable that firms choosing alternative routes for going public are driven by macroeconomic forces. For instance, casual and anecdotal evidence seems to suggest that BDL transactions clustered through time and across industries ${ }^{3}$. In addition, there is evidence in the literature (see, for example, Gleason et al. 2006, Adjei et al. 2008, Floros 2008, Capentier and Suret 2009) that firms opting for the backdoor route are primarily small firms. Consequently, an appealing question to consider is after controlling for the timing, industry and firm size, what are the important determinants of the route choice decision of going-public firms? For the purposes of constructing the control IPO sample, the timing variable is based on the listing year. The industry variable is based on the 2-digit GICS sector. The size variable is based on the total assets of the firms at listing.

The initial sample of IPO firms is obtained from the Connect-4 database (for the years 1994-2007) and from SDC Platinum (for the years 1992-1993). This is supplemented by IPO data made available by Gerry Gallery for the time period 1994-2007. After elimination of duplicates and IPOs that have no data available, the final sample contains 1,660 IPOs that went public during the period 1992-2007. This compares with a total of 200 firms in the BDL sample over the same time period.

The matching procedure is conducted as follows. For each firm in the BDL sample, a matching IPO firm which went public in the same year, belonged to the same GICS sector and had similar total assets is chosen. However, given the fact that the number of IPOs on the ASX in certain years over the sampling period is small, at times it may be difficult to find a matching IPO firm that operates in the same industry sector and has similar size in a particular year. To circumvent this problem, the definition of industry sector is broadened to

\footnotetext{
${ }^{3}$ The most noticeable episode is the backdoor listing of internet firms using mining companies as shells during the dotcom era of 1999-2000.
} 
collapse the 10 GICS sectors into three categories, viz., extractives, industrials and financials, when a matching firm within the conventional GICS sector cannot be found.

\subsection{Choice model}

By pooling both the BDL and the matched IPO samples together, the propensity of private firms to go public through the backdoor can be estimated using a logit regression framework. In this setting, the dependent variable is an indicator variable that takes a value of 1 if a firm goes public through the backdoor (BDL) and 0 if it is an IPO. Two groups of explanatory variables are employed, relating to the characteristics of the firm and the transaction. Several variables, relating to the financial characteristics of firms, are thought to impact the route decision of going public transactions. These include balance sheet liquidity, financial leverage, development stage and profitability.

Upon listing, IPO firms may, relative to their BDL counterparts, exhibit a higher level of liquidity since they might have raised larger proceeds from their public offering of shares. In addition, evidence reported by Gleason et al. (2006) suggests that RTO firms tend to have lower liquidity than matched IPOs. Though a case can be made for BDL firms to exhibit a higher level of liquidity if the shell company they have backed into is essentially a "cash box", the fact that many shell companies are financially distressed (to various extents) makes this scenario less plausible. Therefore, a negative relation between balance sheet liquidity and the probability of a BDL is expected. Balance sheet liquidity (LIQ) is proxied by the ratio of cash and equivalents to total assets.

Gleason et al. (2006) find that RTO firms have a higher level of financial leverage then their matched IPO counterparts. It is also possible that BDL firms may be burdened by debt as a result of the assumption of the debt incurred previously by the shell companies. Thus a positive relation is predicted between financial leverage and the propensity of firms going public through the backdoor path. Financial leverage (LEV) is proxied by the balance sheet ratio of total debt to total assets. 
Based on the results of Floros (2008), compared to a sample of penny-stock IPOs, RM firms tend to be smaller and are still operating at a developmental stage. Firms at early developmental stages tend to have weaker revenue-generating capability relative to their asset base. If private firms going public through the backdoor are in fact younger and less developed than their IPO counterparts, then this would be reflected in the relation between sales revenue and asset base. In this study, development stage is proxied by the asset turnover (ATO) ratio (i.e., ratio of sales to total assets), with a higher value of ATO for more developed firms and vice versa. Firms at early development stages are inherently more risky because their business models and operations are still not proven by the market. A negative relation is predicted between the ATO metric and the likelihood of a BDL.

Backdoor listed firms are also likely to be less profitable than the matched IPO firms at the time of going public. One of the initial listing requirements of the ASX requires that firms have to meet either the "profit test" or "asset test" before they can be admitted to the official list. Even though not all firms choosing the IPO route are able to meet the profit test at listing, they are likely to be subject to pre-screening by underwriters and greater scrutiny during the public offering process. On the other hand, not all BDL firms had to fulfil the re-admission requirements and only a subset of them raised equity capital concurrently with the BDL transaction. Taken together, this may suggest that BDL firms are less profitable than the IPO firms. In the choice model specified, profitability is proxied by return on assets (ROA), measured as the ratio of earnings before interest and tax to total assets. It is predicted that firms with a lower ROA are more likely to choose the backdoor route.

IPO transactions have been known for their long and complicated process, which involves the concerted effort of various professional services and regulatory approvals. In contrast, backdoor listing has been promoted by practitioners as a simpler and faster way to achieve a listing status on an exchange. It is therefore expected that BDL transaction completion would be of a shorter duration than a comparable IPO transaction. Evidence presented in Floros (2008) shows that the median duration for RM transactions is 51 days, as opposed 83 days for IPO firms. Following Floros (2008), the duration metric (DURN) in this 
study is measured as the time elapsed (in days) between the first announcement date and the completion date of the transaction (for BDLs) and between the prospectus lodgement date and the listing date on the ASX (for IPOs). For the purposes of the BDL transactions, the completion date is defined as the date the merged entity is re-admitted to trading on the ASX (if re-admission requirements are imposed) or the date following shareholder approval of the transaction (if no re-admission required). As was argued above, a negative relation is expected between duration and the likelihood of a BDL transaction.

Going-public transactions may be accompanied with cashing-outs by the original owners of the private firms. Going public signifies an important milestone in the life-cycle of a firm but it may also represent an exit strategy for the original owners to sell down their stake and realise some of the gains from their initial investment in the firm. In IPO transactions, original owners may choose to sell down their stake in the going-public firm by offering some of their old shares as part of the public offering. However, this may be construed by the market as a negative signal (over-valuation) when insiders choose to cash out. For BDL transactions, cashing-out activities may occur during the reverse takeover process when part of the consideration paid by the shell company to the private firm shareholders is in the form of cash. Accepting the RTO consideration partially in cash would reduce the ownership of the private firm shareholders in the merged entity. To the extent that the reduced ownership would not adversely affect the exercise of effective control by the private firm owners, it is plausible that cashing-out activities would take place. Cashing out using a RTO transaction has the added advantage of avoiding some of the potential negative signal (over-valuation) attached to selldowns by insiders as accepting a partial consideration in cash is common among takeover activities. Whether cashing-out is more common among BDL or IPO transactions is largely an empirical question. However, it may be argued that more developed and profitable firms are more likely to see cashing-out activities by their owners. Thus it is expected that BDL transactions are associated with less cashing-out by insiders (i.e., a negative relation). To capture the impact that cashing-out activities may have on the going-public route decision, a dummy variable (CASH_OUT), which takes a value of 1 if the original shareholders sell 
down part of their shareholding in the firm during the going public transaction and 0 otherwise, is employed.

Retained ownership (RET_OWN) is the percentage stake that private firm owners retained in the listed entity at the time of listing. Floros (2008) finds that RM firms are associated with less change in insider ownership than their IPO counterparts. However, since the change in insider ownership can be affected by both cashing-out activities by owners and dilution resulting from the going-public process, the result would be difficult to interpret if no separate control for either factor is made. For IPO firms, dilution occurs when shares are sold to the public as part of the listing process. For BDL firms, ownership dilution may occur twice - once during the RTO which would result in the shell company shareholders owning part of the merged entity and a possible second dilution if the backdoored firm also undertakes capital raisings concurrently with the BDL transaction. As evidence from section 4 shows, 78.7 percent of the transactions in the BDL sample involve concurrent capital raisings. Thus it is conceivable that original shareholders of BDL firms would end up having a lower level of retained ownership in the listed entity at the time of listing than their IPO counterparts. Thus a negative relation is expected between retained ownership and the probability of a BDL transaction.

It is well documented in the literature that IPO firms suffered underpricing, which represents a significant cost of going public. Proponents of alternative ways for going public argue that this significant cost of underpricing can be reduced or avoided by doing a backdoor listing instead. Indeed, Gleason et al. (2006) show that RTO firms have a mean (median) first trading day return of 7.88 (2.12) percent, as compared to 23.05 (9.15) percent for control IPO sample. To examine this conjecture, first-day return (DAY1_RET) for both the BDL and IPO samples is constructed, following Gleason et al. (2005). For firms with no concurrent capital raisings, the metric is measured as the change in closing stock price on the first full trading day after completion (either day after shareholder approval or re-admission to ASX) from the day prior. For transactions that also involved concurrent capital raisings, first-day return is calculated as the change in price at the close of the first trading day from the offer price. Since 
all IPO firms involved an offering of shares prior to listing, their first-day return is calculated in the same way as the capital-raising BDL firms. It is expected that BDL firms would have a lower first-day return (underpricing) than the controlled IPO firms, i.e., a negative relation.

Since not all BDL transactions involve raising capital, it is generally expected that IPO firms as a group would raise more proceeds from their public offerings than the BDL sample. However, whether capital-raising BDL transactions raise less proceeds than their controlled IPO counterparts is also of interest. Given the higher level of publicity and more extensive marketing campaign associated with IPO issues, it is expected that the IPOs would still raise relatively more capital during the going-public transaction. To control for the differential impact that the size of proceeds (PRCDS) has on the route decision, the natural logarithm of proceeds raised during the going-public transaction is included as an explanatory variable in the logit regression model. In addition, since the size of the proceeds raised is likely to be affected by whether an underwriter is present, an underwriter dummy variable (UNDERWTR), which takes a value of 1 if the issue is underwritten and 0 otherwise, is included as an additional control variable. An underwriter is expected to be more frequently found in IPO transactions than in capital-raising BDL transactions.

Besides the above firm-specific and deal-specific factors, two additional variables are included to control for the potential bias introduced as a result of imperfect matching between the BDL and IPO sample. The first variable controls for cross-sectional differences in size, as proxied by the natural logarithm of total assets (ASSETS), obtained from the first post-listing balance sheet. The second variable is a control for high-tech companies. It is proxied by an indicator variable (TECH) which takes a value of 1 if the private firm is engaged in internet, information technology, telecommunications or biotechnology related businesses.

The cross-sectional model for the propensity of private firms to use a BDL transaction (rather than an IPO) to go public is specified as follows: 


$$
\begin{aligned}
\operatorname{Pr}\left(B D L_{i}\right)=\alpha_{i} & +\beta_{1} \operatorname{Ln}(\text { ASSETS })_{i}+\beta_{2} \text { TECH }_{i}+\beta_{3} L I Q_{i}+\beta_{4} L E V_{i}+\beta_{5} \text { ATO }_{i}+\beta_{6} R O A_{i} \\
& +\beta_{7} \operatorname{Ln}(\text { DURN })_{i}+\beta_{8} \text { RET_OWN }_{i}+\beta_{9} D A Y 1_{-} R E T_{i}+\beta_{10} \operatorname{Ln}(P R C D S)_{i} \\
& +\beta_{11} \text { UNDERWTR }_{i}+\varepsilon_{i}
\end{aligned}
$$

The coefficients of the explanatory variables are estimated in a logit regression framework using a pooled sample of BDL and matched IPO firms. The dependent variable is an indicator variable $(\mathrm{BDL}=1 ; \mathrm{IPO}=0)$. The results are reported in section 4.4 below.

\subsection{Data}

Accounting input variables are sourced from the first set of financial statements postlisting, obtained from Aspect/Huntley's FinAnalysis database. Where financial statement data is missing from FinAnalysis, information is obtained from the relevant annual reports. Information on the gross proceeds raised and underwriter is taken from the prospectus and verified with information from Aspect/Huntley's DatAnalysis and company announcements through the Signal G/Image Signal platform. Daily stock price data for computing the firstday return of the BDL and IPO firms is obtained from the SIRCA CRD database.

Ideally, for the choice model to have any predictive power, all firm-specific accounting variables should be based on the pre-transaction (i.e., ex ante) financial statement of the private firm. However, pre-transaction financial data for the private firms in the BDL sample is not usually available. In most cases, only selected balance sheet items are provided with no data at all from the income statement. The situation for the IPO sample is better but still less than desirable. This is particularly true for IPO firms that went public by meeting the assets test of the listing requirements. These IPO firms tend to have a short history and limited operations. Therefore, relying on pre-listing financial data of the private firms would seriously hamper the number of observations that can be used in estimating the choice model. As an alternative, data for accounting-related variables from the first set of financial 
statements after going public is used. This set of financial data would tend to incorporate the impact of a partial year of post-listing operating results and the proceeds raised from the going public transaction in the estimation of the logit model. For robustness checks, the natural logarithm of the proceeds raised is included as an additional control variable in some model specifications.

In the univariate and multivariate analyses that follow, only non-financial companies are included in the final sample. Financial firms typically have distinctive operating and financial characteristics compared with firms in other industries and the structure of their financial statements and the information disclosed therein tend to be different as well. Pooling financial and industrial firms together would render the results difficult to interpret. Thus all financial firms are excluded from the final sample. The exclusion of financial firms results in the final sample consisting of 175 BDL firms and 175 IPO firms matched on year, industry and size. In addition, a cursory check of the summary statistics for the BDL sample firms reveals that the three ratios of LEV, ATO and ROA are plagued by extreme values, resulting in their respective pairwise correlations being close to unity. Further research reveals that these extreme results are driven by one outlying firm which has a total asset value of a mere $\$ 10,801$. When this outlier is deleted from the sample, the summary statistics and the pairwise correlation of the three ratios become more in line with the corresponding measures for the matched IPO firms. Therefore, the final sample to be used in the analysis consists of $174 \mathrm{BDL}$ firms together with their matched IPO counterparts.

\section{Results}

\subsection{Descriptive statistics}

Figure 1 plots the distribution of the 200 BDL transactions occurring on the ASX over the period 1992-2007, together with the distribution of IPO transactions for comparison. The figure reveals a generally quiet epoch of BDL activity in the first half of the sampling period 
and a more active time period in the second half, with a clear break in 1999. There were generally less than 10 BDL transactions completed per year in each of the years from 1992 to 1998. The lowest number is 3 (in 1993) and highest is 8 (in 1994). Starting from 1999, there appears to be an increase in backdoor listing activities on the ASX. The number of transactions almost doubled from 1998 (7 cases) to 1999 (13 cases) and further surged and peaked at 32 cases in the year of 2000 . The number started to drop in 2001 (17 cases) but remained at a relatively high level (above 20 cases) in each of the years of 2002-2004. Towards the end of the sampling period, backdoor listings appear to have lost favour, with on average, one transaction per month in both of the years 2005 and 2006. During the last year (2007), the number of transactions dropped back to below 10 (7 cases), similar to what it was in the pre-1999 era. On the whole, the 1992-1998 sub-period accounts for a total of $41 \mathrm{BDL}$ cases (or 20.5 percent) while the 1999-2007 sub-period accounts for 159 cases or 79.5 percent of the overall sample. Australian IPO activity has also gone through periods of relatively hot and cold markets, with troughs observed in the years of 1992, 1995, 1998 and 2001, and peaks in 1994, 1997, 2000 and 2008. Another noticeable trend is that the number of IPOs has increased substantially towards the end of the sample period, with a spike observed in 2007, corresponding to a total of 249 firms floated on the ASX by means of an IPO in that year alone. $^{4}$

By way of comparison, Table 2 tabulates the number of BDL and IPO transactions across the sample period. In addition, the two types of transactions are summed together to obtain the total number of firms going public either through the frontdoor or the backdoor. On a yearly basis, backdoor listing ranges from a low of 2.7 percent (in 2007) to a peak of 25.8 percent (in 2002). For the overall sample period, BDL transactions represent 10.8 percent of all going-public transactions on the ASX.

Figure 2 plots the distribution of going-public transactions across industry sectors. Based on the 2-digit GICS classification, IPO firms seem to be heavily represented in the energy

\footnotetext{
${ }^{4}$ The increased IPO activity over the period 2004-2008 was largely driven by the mining boom. The percentage of mining IPOs surged from roughly 29 percent in 2004 to nearly 48 percent in 2007. If firms from the energy sector are also included, the percentage jumps to in excess of 63 percent in 2007.
} 
(G10), materials (G15) and financials (G40) sectors, whereas BDL firms are more prevalent in the health care (G35), information technology (G45) and telecommunications (G50) sectors. This seems consistent with the view that BDL transactions are popular among higher risk technology firms. On the other hand, private firms from more traditional industries (e.g., resources and financials) prefer to go public through an IPO.

Table 3 reports the summary statistics of selected characteristics of the 174 non-financial BDL transactions together with the matched IPO sample, matching on year, industry and size. The BDL sample has a mean (median) total assets of $\$ 92.2$ (\$16.7) million, compared to $\$ 59.9$ (\$17.3) million for the matched IPO firms. Despite the apparently large disparity in mean value, the difference is not significant as confirmed by a two-sample $t$-test $(t=-0942, p$ value $=0.3469)$. A non-parametric Wilcoxon rank-sum test confirms that the median size of the two samples is not significantly different at conventional levels $(z=-0.116, p$-value $=$ 0.9075). This result tends to affirm that the two samples are reasonably well matched on size, as proxied by the post-listing total assets.

Table 3 reveals that the BDL sample is more dominated by technology firms than its IPO counterparts. This can be seen from a larger value for both the mean and median of the TECH dummy variable for the BDL sample firms. The difference between the two samples is strongly significant ( $p$-value $<0.01$, two-tailed) for both the mean and median value. On average, 56.3 percent of the firms in the BDL sample are engaged in technology-related businesses while 41.4 percent of the matched IPO firms are technology-related. This is the case despite the fact that the two samples are matched on the 2-digit GICS industry sector.

In terms of financial characteristics, there is some evidence that firms in the BDL sample have a lower level of balance sheet liquidity, a smaller asset turnover ratio and a lower (more negative) level of profitability, as measured by the return on assets ratio, than their IPO counterparts. The difference in median values between the two samples is strongly significant ( $p$-value $<0.01$, two-tailed) for all three financial ratios. As for financial leverage, both the mean and the median value of the BDL firms are smaller than the IPO firms, though the results are not statistically significant. 
Contrary to common belief, BDL transactions take longer than IPO transactions to complete. Measuring from the first announcement date till the date of completion, it takes a mean (median) duration of 162.9 (130.5) days for a BDL transaction to be concluded whereas, for the matched IPO sample, Table 3 shows that the mean (median) duration, as measured from the prospectus lodgement date till the first date of trading, is 54.5 (50) days. The difference between the two samples is highly significant for both the mean and the median values ( $p$-value $<0.0001$, two-tailed).

In regards to ownership retained by shareholders of the privately-held firms in the listed issuers, BDL firms tend to have a lower level of retained ownership than the matched IPO sample and the results are statistically significant at the 0.0001 level (two-tailed). The mean (median) value for the BDL and IPO sample is 52.3 (52.8) and 61.3 (64.9) percent, respectively. The lower level of retained ownership for BDL firms could be explained by the fact that, by design, original shareholders of the shell companies would almost invariably hold an equity stake in the post-BDL merged entity. In addition, the merged BDL firms may need to issue shares in order to meet the shareholder spread requirement or raise fresh equity capital. This would lead to further dilution of retained ownership.

BDL transactions are more likely to involve partial cashing-out by owners of the private firms than the matched IPO transactions. On average, 28.7 percent of the BDL transactions involve cash as part of the overall consideration paid by the shell companies. In contrast, only 14.9 percent of the IPOs are associated with the offer of existing shares by their original shareholders. The difference between the two samples is again confirmed by both the parametric and non-parametric tests, with significance at less than the 0.01 level (two-tailed). The greater prevalence of cashing-out associated with BDL transactions could help explain the lower level of ownership retained by the private firm owners.

Table 3 reveals that both BDL firms and their matched IPO counterparts have very similar mean first-day return (approximately 24.4 percent). However, the latter tend to have a larger median value (10.5 percent) than the former (5.0 percent) and the difference is statistically significant ( $p$-value $<0.05$, two-tailed). The inconsistent result between the mean 
and median values suggests that the computed first-day return for the BDL sample is relatively more skewed to the right (as compared to the IPO sample) so that the mean is larger than the median.

It is interesting to note that of the $174 \mathrm{BDL}$ cases, prospectus requirement is mandated in 137 of them (or 78.7 percent). This is in stark contrast to the evidence for the North American markets and would have implication for the information environment of these BDL firms. Not all BDL transactions involve concurrent capital raisings. As Table 3 shows, 137 BDL firms (out of a total of 174) undertook concurrent capital raisings during the going-public transaction, whereas all IPO firms did a public offer and raised fresh equity capital. In terms of the size of the proceeds, BDL firms tend to raise less capital, with a mean (median) value of $\$ 7.54$ (\$4.08) million, compared to $\$ 26.20$ (\$8.66) million for the IPO sample, and the difference is significant at less than the $0.05(0.0001)$ level. The fact that not all BDL transactions concurrently raised capital and that the size of the proceeds is generally smaller would also help explain the lower level of balance sheet liquidity observed for the BDL firms.

For those $137 \mathrm{BDL}$ transactions that did raise capital concurrently, 31.4 percent engaged the services of an underwriter. This compares with 64.4 percent for the IPO sample. Not surprisingly, the difference between the two samples for the UNDERWTR measure is highly significant for both the mean and the median value ( $p$-value $<0.0001$, two-tailed). It is, however, important to note that not all BDL-related capital raisings are necessarily public offers. Private placements of shares, which typically would not involve the use of underwriters, are common among BDL firms. This would contribute to the lower utilisation of underwriters in BDL-related capital raisings.

\subsection{Duration of transaction}

Table 4 compares the length of time (in days) that private firms take to complete a BDL and IPO transaction. For BDLs, transaction duration is measured as the number of days between the first announcement date and the completion date. For all 174 firms in the sample, 
the mean (median) duration is 162.9 (130.5) days. For transactions that did not require readmission by the ASX, the mean (median) duration is 97.4 (87) days whereas the value is 180.6 (143) when re-admission is required. The mean (median) duration is 154.0 (128) days for firms that did not raise any equity capital and is 184.2 (153) days when capital was raised in the process. Based on capital-raising types, transactions involving public offers do not seem of longer duration, with a mean (median) value of 185.2 (153) days, which is similar to the corresponding measure for the overall capital-raising subsample .

Based on their industry experience, Kuo and Humphrey (2002) provide an indicative timetable for a typical backdoor listing transaction on the ASX. Their process starts with the appointment of advisors and ends with the re-listing of the backdoor firm on ASX, but excludes any concurrent capital raisings. Their experience suggests an indicative duration of 12 weeks (or 84 days). This compares with a median of 130.5 days for all the firms in the BDL sample and 143 days for cases in which re-admission are required. For cases with no capital raisings, the median duration of 128 days is still much longer than Kuo and Humphrey (2002) indicated. Their indicative duration of 84 days is comparable to that of the no readmission subsample, with a median duration of 87 days. Note that the longest task in their indicative timetable is the drafting of the prospectus, which takes up to 5 weeks (or 35 days) to complete.

For the IPO sample, transaction duration is measured as the length of time (in days) between the date of lodgement of prospectus and the listing date. For all IPO firms in the matching sample, the mean (median) duration is 54.5 (50) days. The above results seem to strongly suggest that private firms generally take much longer to complete a BDL than an IPO. Both a parametric $t$-test $(t$-statistic $=-12.511)$ for the mean and a non-parametric Wilcoxon rank-sum test $(z$-statistic $=-13.102)$ for the median confirm that the duration is significantly different ( $p$-value $<0.0001$, two-tailed). This is still the case even if no re-admission requirement is imposed by ASX on the backdoor firm.

Note that the way IPO duration is measured in the above table may in fact understate the time that it takes to complete the IPO process, which starts typically not from the date of the 
prospectus lodgement, but from the date of the kick-off meeting between the IPO firm and the investment bank/underwriter or even earlier. Evidence from Floros (2008) on the US IPO market for penny stocks shows that the median duration between the first registration of the prospectus and the offer date and between the kick-off meeting and the offer date is around 83 and 125 days, respectively. In other words, the average time between the kick-off meeting and the registration of prospectus is approximately 42 days. This 42 -day period is consistent with the indicative timetable of Kuo and Humphrey (2002), who suggest five weeks for prospectus drafting and another week or so for lodgement with ASIC (i.e., a total of 42 days).

For robustness checks, this extra duration of 42 days, representing the average time between the kick-off meeting and the registration of prospectus, is added to the original duration measure. Results from Table 4 show that this new duration measure for IPOs has a mean (median) of 96.5 (92) days, which is still significantly (with $p$-value $<0.0001$, twotailed) shorter than the duration measure for the BDL firms $(t$-statistic $=-7.666, z$-statistic $=-$ $7.051)$.

Of course one can also argue that the IPO process might have started much earlier than the kick-off meeting. Private firms might have spent years preparing themselves for the IPO. However, the same argument also applies to the backdoored private firms. The difficulty is no objective measure is available to address this problem.

\subsection{First-day return}

Similar to transaction duration, the first-day return metric for the BDL sample is computed differently across the sample, depending on whether firms also undertake concurrent capital raisings during the process. The first-day return metric for the BDL firms is tabulated in Table 5 below for different subsamples according to the transaction attributes. Also evident in Table 5 is a significant difference between BDL and IPO firms in the no readmissions and/or no capital raisings subsamples. For the majority of firms which require readmissions or undertake concurrent capital raisings, no significant difference in first-day 
return can be detected. Thus evidence seems to suggest that both BDL and IPO firms experience a similar level of underpricing during their going-public transaction.

\subsection{Logit analysis}

Table 6 reports the results from the logit regression analysis. Four sets of results are presented, corresponding to the different subsamples used. Besides using the full sample, the analysis is repeated for the (1) re-admissions subsample, (2) re-admissions and capital raisings subsample, and (3) re-admissions and public offers subsample, with each of these subsamples increasingly resembling with their IPO counterparts. In fact, it can be argued that BDL firms which have to re-meet the initial listing requirements and concurrently conduct capital raisings through a public offer before their shares are re-admitted to trading on the ASX are essentially de facto IPOs. Since not all BDL firms involved concurrent capital raisings, the two factors relating to the proceeds raised and the use of an underwriter are only included for the two subsamples involving raising new equity capital.

Columns 1 and 2 of Table 6 present the results estimated for the full sample of BDL and IPO firms. Consistent with expectations, the coefficient for the natural logarithm of total assets is negative, suggesting larger firms tend to go public via the IPO route, but the results are not statistically significant. The coefficient for the TECH dummy variable is positive and highly significant (at the 0.01 level), suggesting that high-tech firms are more likely to go public through the backdoor. This result is also consistent with the univariate analysis which reveals a higher proportion of technology firms in the BDL than in the IPO sample. As for the financial characteristics, BDL firms tend to have lower LIQ (significant at the 0.01 level), lower ATO (significant at the 0.01 level) and lower ROA (significant at the 0.1 level). However, no significant results are found for leverage. In other words, when compared with their IPO counterparts, BDL firms tend to have lower level of balance sheet liquidity. They are also more likely to be at a development stage (as reflected by the lower level of asset turnover) and less profitable in their operations. Turning to the transaction-specific factors, 
BDL transactions generally take a longer duration to complete and tend to result in a lower level of retained ownership by the private firm owners in the listed entity. They are also more likely to be associated with private firm owners cashing out part of their stake in the business. The coefficients estimated for these three factors are all strongly significant (at the 0.01 level). Nevertheless, no significant result can be established for the first-day return as a differentiating factor in the choice of route for going public. The logit regression results are similar when the re-admissions only BDL subsample (together with their matched IPOs) is used. As column 3 and 4 show, except for the ROA factor, the same results hold for the significant factors as identified for the full sample of firms.

Except for slight differences in the significance of the coefficients estimated, the results for the two capital raising subsamples are similar to each other. As expected, the two factors of $\operatorname{Ln}(\mathrm{PRCDS})$ and UNDERWTR are negative and significant, suggesting that IPO firms raise more proceeds and are more likely to have used an underwriter during their public offering of shares. When these two factors are excluded from the model, the results (column 5 and 7) are broadly consistent with those found for the full and re-admissions sample. However, after controlling for the two capital raising variables (column 6 and 8), two noticeable changes emerge. The size proxy becomes positive and highly significant (at the 0.01 level) while the liquidity factor loses significance. Recall that the BDL and IPO sample firms are matched on post-listing total assets, which include any proceeds raised during their going-public transaction. To the extent that IPO firms raised more proceeds during their public offering (which is consistent with the negative and significant coefficient estimated) than their BDL counterparts, these results can be taken to imply that the latter group is actually larger (in terms of total assets) than the former group on a pre-money basis. After controlling for the impact of the capital raised, the LIQ factor also becomes insignificant. In other words, on a pre-money basis, IPO firms are not necessarily more liquid than their BDL counterparts. There is also some weak evidence (significant at the 0.1 level) that IPO firms tend to be more highly levered than their capital-raising BDL counterparts. However, when proceeds from the capital raisings is controlled for, no significant results are identified. 
Overall, the logit regression model performs reasonably well in differentiating firms between backdoor and front-door listing. The pseudo $R$-squared of the model ranges from 0.2291 for the full sample to 0.5987 for the re-admissions and capital raisings subsample, with the corresponding percentage of firms correctly classified by the model being 74.14 percent and 88.84 percent, respectively.

To gauge the economic significance of explanatory factors for choosing the BDL over the IPO route for going public, the marginal effect of each individual factor is evaluated as follows. Using the coefficients estimated from the logit regression models, the probability of an "average" private firm ending up using the backdoor route can first be evaluated by setting each individual factor equal to their respective (pooled) median value. This is the base case scenario. The marginal effect of a particular factor can then be gauged by computing the change in probability resulting from a one standard deviation change (decrease) from the pooled median in the value of the factor, while holding all other variables constant at their median value. If a particular factor is an indicator variable, its marginal effect can only be evaluated by a discrete change in value (i.e., from zero to one or from one to zero, depending on what its median value is). This procedure is repeated for each of the factors in the logit models and the results are tabulated in Table 7.

For the full sample of firms, the most significant determinant of firms opting for the backdoor path is CASH_OUT. Controlling for other factors, its effect on the marginal probability of a BDL (as opposed to an IPO) is 0.2376 . This is followed by TECH $(0.2288)$ and ATO (0.2062). The results are similar but stronger for the re-admissions subsample. Again, BDL transactions are more likely to involve cashing-out activities (0.3450) and hightech firms (0.2513). However, instead of ATO, transaction duration comes up as the third most significant factor. A one standard deviation decrease in $\operatorname{Ln}(\mathrm{DURN})$ would result in a drop in the probability of a BDL transaction by 0.2430 .

The size factor only reveals its significance in the two re-admissions and capital raisings subsamples. After controlling for the amount of proceeds raised, a one standard deviation decrease in Ln(ASSETS) corresponds with a marginal probability of -0.4561 and -0.3082 for 
the "all offer types" and "public offers only" subsamples, respectively. This suggests that BDL firms are in fact larger than their matched IPOs on a pre-money basis. Other significant determinants of BDLs include UNDERWTR and $\operatorname{Ln}(\mathrm{DURN})$ for the "all offer types" subsample and Ln(PRCDS) and CASH_OUT for the "public offers only" subsample.

\section{Robustness tests}

One concern regarding the matched sample approach is that if BDL firms are typically smaller firms, then matching the IPO firms with the BDL firms on size would render the matched IPO sample not representative of the overall population. This may limit the extent to which the above results can be generalised.

\subsection{Checks based on IPO size deciles}

To address the above concern, the post-listing total assets (converted to 2007 constant dollars) of all the 1,660 IPO firms are sorted into 10 size deciles. The sample of BDL firms is then assigned to these deciles according to their post-transaction total assets (also converted to 2007 constant dollar). If the claim that BDL firms are smaller firms as compared to their IPO counterparts, then BDL firms should be clustered in the left tail of the size deciles.

Figure 3 presents a plot of the distribution of the percentage of BDL firms across the 10 IPO size deciles. As can be seen in the plot, the BDL firms are well represented across all 10 deciles. Instead of being skewed to the left (smaller size), the BDL sample demonstrates a typical bell-shaped curve, with a higher density observed across the mid-range $(4,5,6,7$ and 8) size deciles and lower density observed in both tails. This evidence seems to suggest that the results based on the size-matched IPO sample is not particularly biased towards smaller firms. 


\subsection{Robustness based on IPO sample randomised on size}

To further ascertain the sensitivity of the choice model results, a second sample of IPO firms matched on year and industry, but not size, with the BDL firms is constructed. The same choice model is then re-estimated using this new set of IPO firms.

Table 8 reports the summary statistics for the non-size matched IPO sample. The randomisation on size yields a sample of IPOs that are, on average, larger in total assets. The mean (median) size of the IPO firms is \$101 (\$20.5) million. This compares with a mean (median) value of \$92.2 (\$16.7) million for the BDL sample and \$59.9 (\$17.3) million for the size-matched IPO sample.

Other than size, the only other noticeable difference from the size-matched sample is that the proportion of IPO transactions involving cashing-out activities by private firm owners has increased substantially, to 25.9 percent. This contrasts with 14.9 percent for the size-matched sample and 28.7 percent for the BDL sample. This set of combined results seems to suggest that original shareholders of larger IPO firms are more likely to sell down their stake during the public offering process, relative to smaller IPO firms. However, controlling for size, owners of backdoored private firms are still more likely to partially cash out their equity stake.

Table 9 reports the results from the logit regression analysis. Overall, the results are broadly consistent with the previous results found for the size-matched IPO sample, with a few notable exceptions. The negative coefficient estimated for ATO and ROA appears to be stronger and more significant across the various subsamples than before. In addition, the coefficient for the LIQ factor remains negative and significant even after controlling for the size of the proceeds raised. Taken together, these results imply that larger IPO firms are more developed and financially stronger, with a higher level of balance sheet liquidity and better profitability. Consistent with the univariate results in Table 8 , no significant coefficient is found for the CASH OUT variable in the multivariate framework. It is interesting to note that the UNDERWTR variable has also become insignificant after controlling for the other determining factors. 


\section{Conclusion}

There are alternative ways for private firms to go public and an IPO is not the only option. Backdoor listing is another popular and viable path for firms desiring an exchange listing status. This paper develops an empirical model of the factors that could potentially influence the decision of firms committed to going public when choosing between an IPO and $\mathrm{BDL}$ as their path. Critics argue that RTOs or RMs are not directly comparable to IPOs as the former transactions typically do not require prospectus disclosure and undertake no capital raisings (especially public offerings) during the process. By exploiting the unique institutional features of Australian backdoor listing transactions (e.g., re-admissions requirement, prospectus disclosure, concurrent capital raisings), the results from this study hold the potential to provide a more meaningful comparison between the two alternative routes of going public.

Based on the extant literature and the special features of the Australian capital markets, a set of firm-specific characteristics and deal-related factors is identified as potential determinants of the route decision. A choice model is then estimated using a unique, handcollected sample of BDL transactions in a logit regression framework. Overall, results show that BDL firms are not necessarily smaller than IPO firms in terms of size (as proxied by post-listing total assets). After controlling for the amount of proceeds raised during the goingpublic transaction, there is evidence that BDL firms are larger than their IPO counterparts. This could result from the fact that the total assets of the BDL firm represent the combined assets of both the shell company and the private firm. If only the size of the pre-transaction private firms is compared, the conclusion could be different.

In terms of firm characteristics, a BDL transaction is more likely to be associated with a private firm engaged in a high-tech business. In addition, BDL firms generally tend to be less liquid, at an earlier development stage and less profitable than their matched IPO counterparts.

Contrary to popular belief, Australian BDLs take longer to complete than IPOs and this 
result holds across different BDL subsamples. The implication is that going public through the backdoor may not necessarily be easier and faster than a front-door listing via an IPO.

In terms of deal design, BDL transactions are involved with more cashing-out activities by private firm owners. Notwithstanding the more frequent cashing-out, these insiders have a lower retained ownership in the listed entity at the time of listing. This result contradicts the notion that owners of more developed firms (i.e., IPO firms) are more likely to sell down their stake and cash out than insiders of firms that are still developing.

When only BDL subsamples subject to the re-admission requirement and concurrent capital raisings are examined, the matched IPO firms tend to raise a larger amount of proceeds. And it is unsurprising that IPO firms are more likely to engage the services of an underwriter to assist in the capital raising exercise.

Finally, no significant difference in the degree of underpricing (first-day return) between BDLs and IPOs can be established across the subsamples. This result casts doubt on the claim that backdoor listing can help avoid or minimise the costs of underpricing suffered by IPO firms when going public. 


\section{References}

Adjei, F., K. Cyree, and M. Walker, 2008, The determinants and survival of reverse mergers vs. IPOs, Journal of Economics and Finance 32: 176-194.

Brau, J., B. Francis, and N. Kohers, 2003, The choice of IPO versus takeover: empirical evidence, Journal of Business 76: 583-612.

Carpentier, C., D. Cumming, and J.-M. Suret, 2009, The value of capital market regulation: IPOs versus reverse mergers, working paper (CIRANO) [online]. Available: http://ssrn.com/abstract $=1356324$

Carpentier, C., and J.-M. Suret, 2009, Entrepreneurial equity financing and securities regulation: an empirical analysis, working paper (CIRANO) [online]. Available: http:// ssrn.com/abstract $=1362645$

Derrien, F., and A. Kecskes, 2007, The initial public offering of listed firms, Journal of Finance 62: 447-479.

Floros, I., 2008, Two essays on alternative mechanisms to going public, unpublished $P h D$ thesis, University of Pittsburgh.

Gleason, K. C., R. Jain, and L. Rosenthal, 2006, Alternatives for going public: evidence from reverse takeovers, self-underwritten IPOs, and traditional IPOs, [online]. Available: http://ssrn.com/abstract=890714

Jensen, M., and R. Ruback, 1983, The market for corporate control: the scientific evidence, Journal of Financial Economics 11: 5-50.

Kuo, R., and N. Humphrey, 2002, The growing acceptance of backdoor listings, JASSA, Issue 4 (Summer): 28-32 \& 40.

Poulsen, A., and M. Stegemoller, 2006, Moving from private to public ownership: selling out to public firms vs. initial public offerings [online]. Available: http://ssrn.com/abstract $=624524$

Sjostrom, W., 2008, The truth about reverse mergers, Entrepreneurial Business Law Journal 2: $743-759$. 
Figure 1

BDL vs. IPO Activity on the ASX: 1992-2007

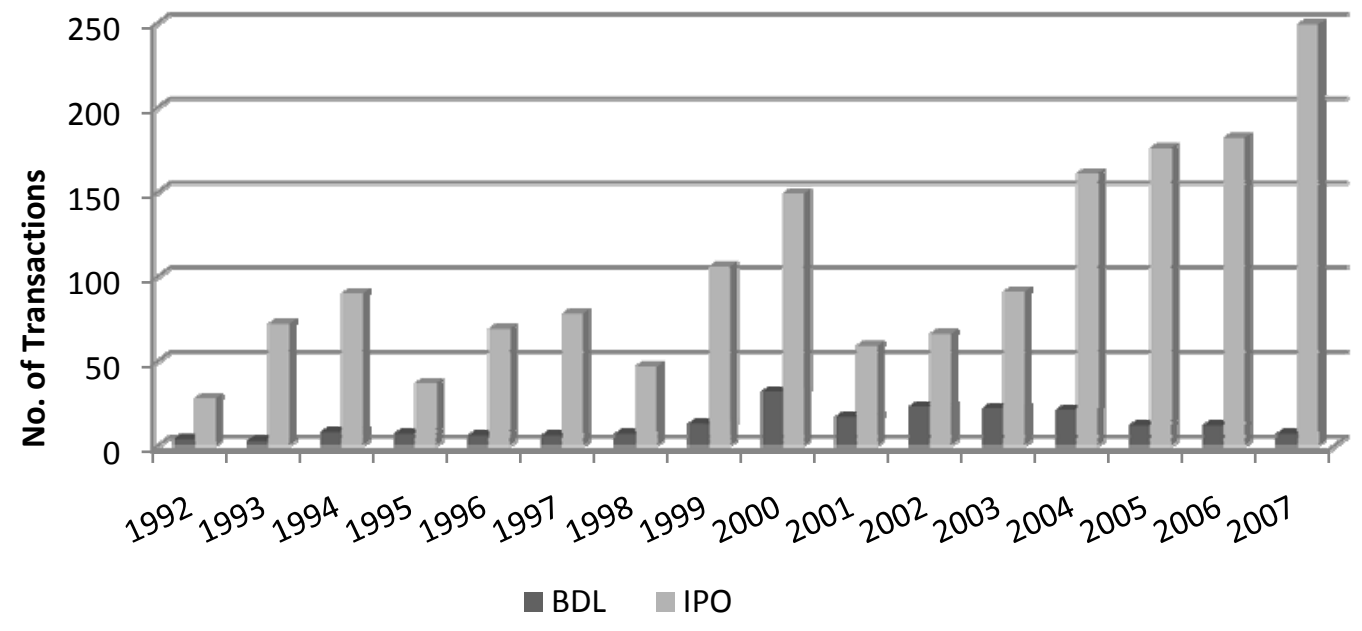

Figure 2

Distribution of BDL and IPO Firms by GICS Sector

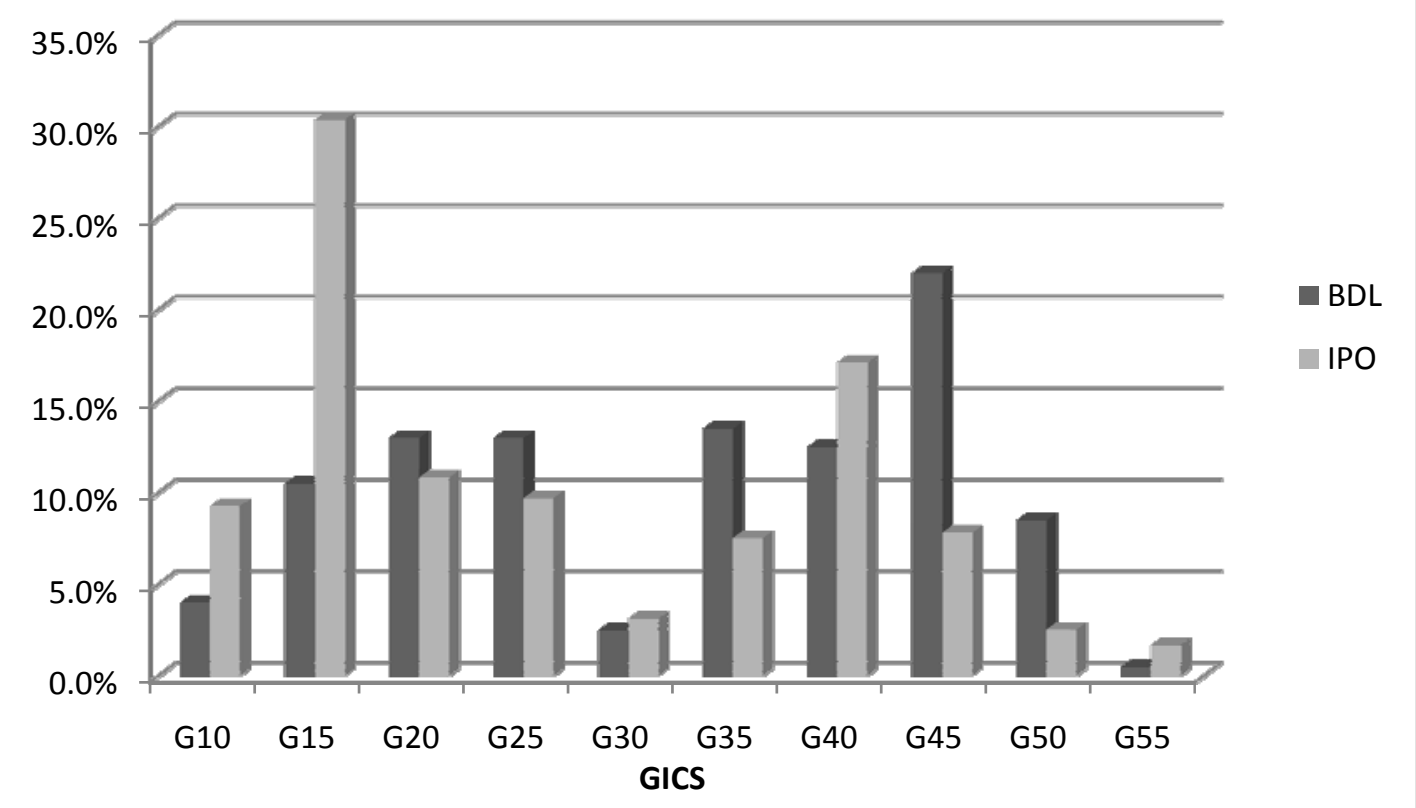


Figure 3

Distribution of BDL Firms Across IPO Size Deciles: 1992-2007

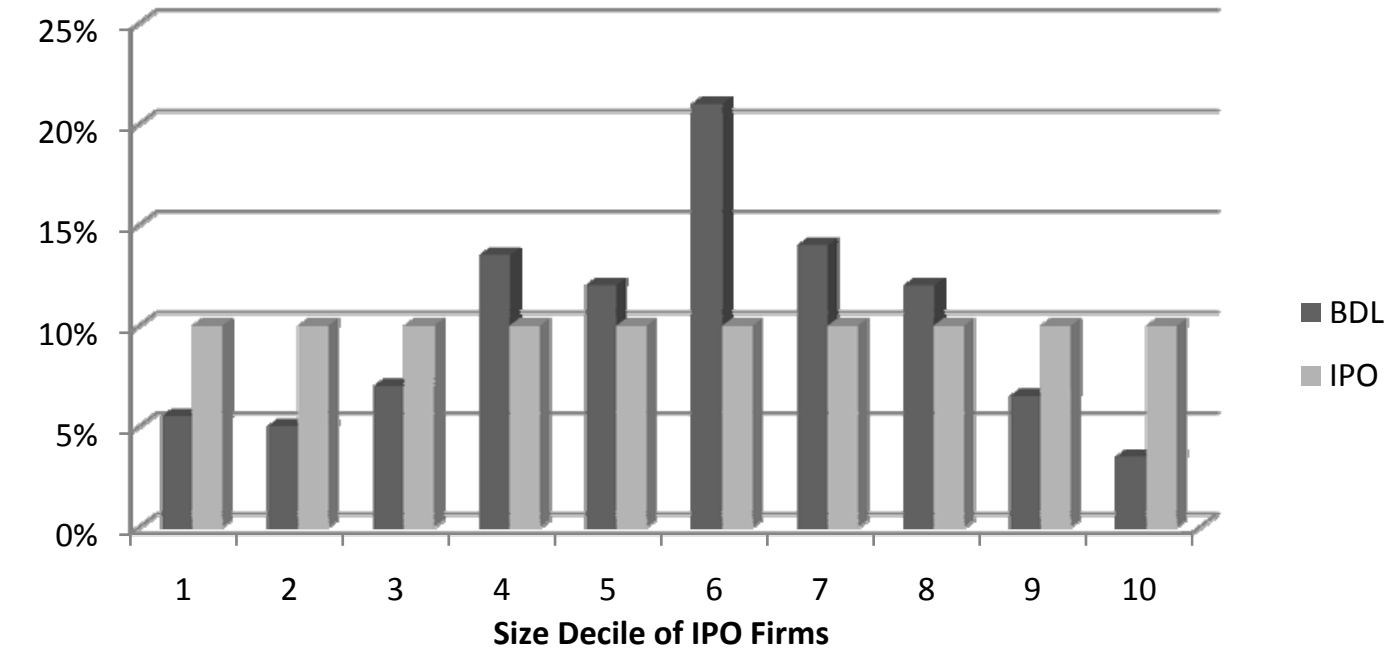


Table 1

Sample Identification of Backdoor Listing Transactions

Preliminary cases through Factiva media search 296

Cases not meeting BDL definition

Confirmed BDL cases from media

Preliminary cases from Zephyr, Bureau van Dijk

Cases not meeting BDL definition

Confirmed BDL cases from Zephyr

All confirmed BDL cases $(183+17)$

Of which: Industrial firms

Table 2

\begin{tabular}{crrrr}
\multicolumn{5}{c}{ Distribution of BDL and IPO Transactions by Year } \\
\hline Year & BDL & IPO & Total & BDL \% \\
& $(1)$ & $(2)$ & $(3)$ & $(4)$ \\
\hline 1992 & 4 & 28 & 32 & $12.5 \%$ \\
1993 & 3 & 72 & 75 & $4.0 \%$ \\
1994 & 8 & 90 & 98 & $8.2 \%$ \\
1995 & 7 & 37 & 44 & $15.9 \%$ \\
1996 & 6 & 69 & 75 & $8.0 \%$ \\
1997 & 6 & 78 & 84 & $7.1 \%$ \\
1998 & 7 & 47 & 54 & $13.0 \%$ \\
1999 & 13 & 106 & 119 & $10.9 \%$ \\
2000 & 32 & 149 & 181 & $17.7 \%$ \\
2001 & 17 & 59 & 76 & $22.4 \%$ \\
2002 & 23 & 66 & 89 & $25.8 \%$ \\
2003 & 22 & 91 & 113 & $19.5 \%$ \\
2004 & 21 & 161 & 182 & $11.5 \%$ \\
2005 & 12 & 176 & 188 & $6.4 \%$ \\
2006 & 12 & 182 & 194 & $6.2 \%$ \\
2007 & 7 & 249 & 256 & $2.7 \%$ \\
\hline All years & 200 & 1660 & 1860 & $10.8 \%$ \\
\hline
\end{tabular}


Table 3

Descriptive Statistics of Explanatory Variables

\begin{tabular}{|c|c|c|c|c|c|c|c|c|c|c|}
\hline & \multicolumn{3}{|c|}{ BDL sample } & \multicolumn{3}{|c|}{ Matched IPO sample } & \multicolumn{2}{|c|}{ 2-sample $t$-test } & \multicolumn{2}{|c|}{ Wilcoxon rank-sum test } \\
\hline & $\mathrm{N}$ & Mean & Median & $\mathrm{N}$ & Mean & Median & $t$-stat & $p$-value & $z$-stat & $p$-value \\
\hline ASSETS (\$m) & 174 & 92.20 & 16.70 & 174 & 59.90 & 17.30 & -0.942 & 0.3469 & -0.116 & 0.9075 \\
\hline LIQ & 174 & 0.212 & 0.131 & 174 & 0.328 & 0.214 & 4.074 & 0.0001 & 3.170 & 0.0015 \\
\hline LEV & 174 & 0.291 & 0.196 & 174 & 0.328 & 0.272 & 0.912 & 0.3626 & 0.983 & 0.3258 \\
\hline DURN (days) & 174 & 162.9 & 130.5 & 174 & 54.5 & 50 & -12.511 & 0.0000 & -13.102 & 0.0000 \\
\hline RET_OWN & 174 & 0.523 & 0.528 & 174 & 0.613 & 0.649 & 3.986 & 0.0001 & 4.552 & 0.0000 \\
\hline CASH_OUT & 174 & 0.287 & 0 & 174 & 0.149 & 0 & -3.149 & 0.0018 & -3.109 & 0.0019 \\
\hline DAY1_RET & 174 & 0.244 & 0.050 & 174 & 0.244 & 0.105 & -0.001 & 0.9993 & 2.338 & 0.0194 \\
\hline
\end{tabular}


Table 4

Duration of BDL and IPO Transactions

\begin{tabular}{lrrrrrr}
\hline & N & Mean & Median & SD & Min & Max \\
\hline BDL firms: & & & & & & \\
Full sample & 174 & 162.9 & 130.5 & 112.6 & 7 & 677 \\
No re-admission & 37 & 97.4 & 87 & 74.9 & 7 & 450 \\
Re-admission & 137 & 180.6 & 143 & 114.7 & 41 & 677 \\
Re-admission \& no raisings & 16 & 154.0 & 128 & 67.3 & 56 & 281 \\
Re-admission \& all raisings & 121 & 184.2 & 153 & 119.3 & 41 & 677 \\
Re-admission \& public offers & 100 & 185.2 & 153 & 121.7 & 41 & 677 \\
& & & & & & \\
PPO firms: & & & & & & \\
Lodgement to listing & 174 & 54.5 & 50 & 19.9 & 23 & 154 \\
Kick-off to listing & 174 & 96.5 & 92 & 19.9 & 65 & 196 \\
\hline
\end{tabular}

Table 5

Comparison of First-day Returns Across Different Subsamples

\begin{tabular}{|c|c|c|c|c|c|c|c|}
\hline & \multirow[b]{2}{*}{$\mathrm{N}$} & \multicolumn{2}{|c|}{ BDL firms } & \multicolumn{2}{|c|}{ Matched IPOs } & \multirow{2}{*}{$\begin{array}{c}t \text {-stat } \\
(p \text {-value })\end{array}$} & \multirow{2}{*}{$\begin{array}{c}z \text {-stat } \\
(p \text {-value }) \\
\end{array}$} \\
\hline & & Mean & Median & Mean & Median & & \\
\hline Full sample & 174 & 0.244 & 0.050 & 0.244 & 0.105 & $\begin{array}{r}-0.001 \\
(0.9993)\end{array}$ & $\begin{array}{r}2.338 \\
(0.0194)\end{array}$ \\
\hline Re-admissions & 137 & 0.299 & 0.075 & 0.220 & 0.100 & $\begin{array}{r}-0.973 \\
(0.3314)\end{array}$ & $\begin{array}{r}1.204 \\
(0.2286)\end{array}$ \\
\hline Capital raisings & 137 & 0.256 & 0.075 & 0.238 & 0.110 & $\begin{array}{r}-0.249 \\
(0.8037)\end{array}$ & $\begin{array}{r}1.054 \\
(0.2921)\end{array}$ \\
\hline Re-admissions \& raisings & 121 & 0.285 & 0.083 & 0.227 & 0.120 & $\begin{array}{r}-0.761 \\
(0.4473)\end{array}$ & $\begin{array}{r}0.686 \\
(0.4930)\end{array}$ \\
\hline Re-admissions \& public offers & 100 & 0.241 & 0.078 & 0.207 & 0.100 & $\begin{array}{r}-0.405 \\
(0.6858)\end{array}$ & $\begin{array}{r}0.784 \\
(0.4331)\end{array}$ \\
\hline No re-admissions & 37 & 0.040 & 0.017 & 0.333 & 0.110 & $\begin{array}{r}2.444 \\
(0.0170)\end{array}$ & $\begin{array}{r}3.129 \\
(0.0018)\end{array}$ \\
\hline No capital raisings & 37 & 0.199 & 0.000 & 0.265 & 0.100 & $\begin{array}{r}0.349 \\
(0.7279)\end{array}$ & $\begin{array}{r}3.411 \\
(0.0006)\end{array}$ \\
\hline No re-admissions \& no raisings & 21 & 0.045 & 0.014 & 0.342 & 0.150 & $\begin{array}{r}2.139 \\
(0.0386)\end{array}$ & $\begin{array}{r}3.115 \\
(0.0018)\end{array}$ \\
\hline
\end{tabular}


Table 6

Choice between Backdoor Listing and initial Public Offering: Logit regression Analysis (Matched IPOs)

\begin{tabular}{|c|c|c|c|c|c|c|c|c|c|}
\hline & \multirow{3}{*}{$\begin{array}{l}\text { Predicted } \\
\text { sign } \\
\end{array}$} & & & & & \multicolumn{4}{|c|}{ Re-admissions \& capital raisings } \\
\hline & & \multicolumn{2}{|c|}{ Full sample } & \multicolumn{2}{|c|}{ Re-admissions } & \multicolumn{2}{|c|}{ All offer types } & \multicolumn{2}{|c|}{ Public offers } \\
\hline & & (1) & (2) & (3) & (4) & (5) & (6) & (7) & $(8)$ \\
\hline \multirow[t]{2}{*}{ CONSTANT } & & 2.007 & $-5.122^{*}$ & 2.887 & $-12.317 * * *$ & $-11.778 * *$ & -5.570 & $-13.029 * *$ & -3.452 \\
\hline & & $(1.06)$ & $(-1.93)$ & $(1.17)$ & $(-3.03)$ & $(-2.54)$ & $(-0.91)$ & $(-2.35)$ & $(-0.48)$ \\
\hline \multirow[t]{2}{*}{ Ln(ASSETS) } & - & -0.078 & -0.010 & -0.117 & -0.019 & 0.019 & $1.824 * * *$ & 0.072 & $1.477 * * *$ \\
\hline & & $(-0.73)$ & $(-0.08)$ & $(-0.83)$ & $(-0.11)$ & $(0.09)$ & (3.97) & $(0.29)$ & $(3.02)$ \\
\hline \multirow[t]{2}{*}{ TECH } & + & $0.790^{* * *}$ & $0.935^{* * *}$ & $0.870^{* * *}$ & $1.027 * * *$ & $1.334 * * *$ & $1.242 * *$ & $1.075^{* *}$ & $1.039^{* *}$ \\
\hline & & (3.14) & (3.40) & (3.08) & (3.01) & (3.38) & $(2.51)$ & $(2.54)$ & $(2.04)$ \\
\hline \multirow[t]{2}{*}{ LIQ } & - & $-2.975 * * *$ & $-2.451 * * *$ & $-3.161 * * *$ & $-2.341 * * *$ & $-3.144 * * *$ & -0.595 & $-3.233 * * *$ & -1.132 \\
\hline & & $(-5.36)$ & $(-4.13)$ & $(-5.13)$ & $(-3.29)$ & $(-3.85)$ & $(-0.57)$ & $(-3.56)$ & $(-0.98)$ \\
\hline \multirow[t]{2}{*}{ LEV } & + & 0.210 & 0.491 & -0.663 & -1.047 & $-1.386^{*}$ & -0.576 & $-1.601^{*}$ & -0.992 \\
\hline & & $(0.40)$ & $(0.96)$ & $(-1.07)$ & $(-1.45)$ & $(-1.71)$ & $(-0.42)$ & $(-1.78)$ & $(-0.71)$ \\
\hline \multirow[t]{2}{*}{ ATO } & - & $-0.783 * * *$ & $-0.732 * * *$ & $-0.735^{* * *}$ & $-0.652^{* *}$ & $-0.888^{* *}$ & $-1.237^{* *}$ & $-0.807^{*}$ & $-0.960 *$ \\
\hline & & $(-3.95)$ & $(-3.61)$ & $(-3.12)$ & $(-2.36)$ & $(-2.27)$ & $(-2.18)$ & $(-1.93)$ & $(-1.66)$ \\
\hline \multirow[t]{2}{*}{ ROA } & - & $-0.419^{*}$ & $-0.434^{*}$ & -0.401 & -0.389 & $-0.939 * *$ & $-1.835 * * *$ & $-0.965^{* *}$ & $-1.661 * * *$ \\
\hline & & $(-1.71)$ & $(-1.70)$ & $(-1.51)$ & $(-1.36)$ & $(-2.15)$ & $(-2.88)$ & $(-2.15)$ & $(-2.66)$ \\
\hline \multirow[t]{2}{*}{ Ln(DURN) } & - & & $1.381 * * *$ & & $2.912 * * *$ & $2.874 * * *$ & $2.937 * * *$ & $3.023 * * *$ & $2.740^{* * *}$ \\
\hline & & & $(4.59)$ & & $(5.75)$ & $(5.29)$ & $(4.79)$ & $(4.89)$ & $(4.27)$ \\
\hline \multirow[t]{2}{*}{ CASH_OUT } & - & & $0.973 * * *$ & & $1.450 * * *$ & $1.335^{* *}$ & $2.010 * * *$ & $1.334 * *$ & $1.811^{* *}$ \\
\hline & & & $(2.85)$ & & (3.09) & $(2.54)$ & $(2.66)$ & $(2.29)$ & $(2.24)$ \\
\hline \multirow[t]{2}{*}{ RET_OWN } & - & & $-1.790 * * *$ & & $-1.383^{*}$ & $-2.871 * * *$ & $-6.956 * * *$ & $-3.060 * * *$ & $-6.390 * * *$ \\
\hline & & & $(-2.96)$ & & $(-1.87)$ & $(-3.31)$ & $(-5.29)$ & $(-3.06)$ & $(-4.53)$ \\
\hline \multirow[t]{2}{*}{ DAY1_RET } & - & & -0.030 & & 0.281 & 0.158 & 0.043 & 0.051 & 0.069 \\
\hline & & & $(-0.15)$ & & $(0.97)$ & $(0.47)$ & $(0.10)$ & $(0.14)$ & $(0.15)$ \\
\hline \multirow[t]{2}{*}{ Ln(PRCDS) } & - & & & & & & $-2.206^{* * *}$ & & $-1.918 * * *$ \\
\hline & & & & & & & $(-5.10)$ & & $(-4.30)$ \\
\hline \multirow[t]{2}{*}{ UNDERWTR } & - & & & & & & $-1.522 * * *$ & & $-1.254 * *$ \\
\hline & & & & & & & $(-3.07)$ & & $(-2.47)$ \\
\hline Observations & & 348 & 348 & 274 & 274 & 242 & 242 & 200 & 200 \\
\hline Log likelihood & & -210.21 & -185.96 & -163.26 & -125.26 & -99.32 & -67.32 & -82.07 & -60.11 \\
\hline LR Chi-squared & & 62.01 & 110.50 & 53.33 & 129.31 & 136.84 & 200.84 & 113.12 & 157.04 \\
\hline Pseudo $R^{2}$ & & 0.1285 & 0.2291 & 0.1404 & 0.3404 & 0.4079 & 0.5987 & 0.4080 & 0.5664 \\
\hline Correctly classified & & 0.6839 & 0.7414 & 0.7044 & 0.8139 & 0.8374 & 0.8884 & 0.8200 & 0.8650 \\
\hline
\end{tabular}


Table 7

Marginal Effect of Individual Factors on the Likelihood of BDL over IPO

\begin{tabular}{lcccc}
\hline & Full sample & Re-admissions & $\begin{array}{c}\text { Re-admissions \& } \\
\text { All offer types }\end{array}$ & $\begin{array}{c}\text { Re-admissions \& } \\
\text { Public offers }\end{array}$ \\
\hline Ln(ASSETS) & 0.0030 & 0.0052 & -0.4561 & -0.3082 \\
TECH & 0.2288 & 0.2513 & -0.2881 & 0.2453 \\
LIQ & 0.1650 & 0.1612 & 0.0308 & 0.0790 \\
LEV & -0.0441 & 0.0906 & 0.0392 & 0.0990 \\
ATO & 0.2062 & 0.1893 & 0.1860 & 0.2681 \\
ROA & 0.0775 & 0.0730 & 0.1752 & 0.2994 \\
Ln(DURN) & -0.1567 & -0.2430 & -0.3420 & -0.2836 \\
RET_OWN & 0.0954 & 0.0710 & 0.1817 & 0.2931 \\
CASH_OUT & 0.2376 & 0.3450 & 0.2130 & 0.3753 \\
DAY1_RET & 0.0046 & -0.0426 & -0.0050 & -0.0100 \\
Ln(PRCDS) & & & 0.2483 & 0.4905 \\
UNDERWTR & & & -0.3561 & -0.2673 \\
\hline
\end{tabular}


Table 8

Descriptive Statistics of Explanatory Variables

\begin{tabular}{|c|c|c|c|c|c|c|c|c|c|c|}
\hline & \multicolumn{3}{|c|}{ BDL sample } & \multicolumn{3}{|c|}{ Random IPO sample } & \multicolumn{2}{|c|}{ 2-sample $t$-test } & \multicolumn{2}{|c|}{ Wilcoxon rank-sum test } \\
\hline & $\mathrm{N}$ & Mean & Median & $\mathrm{N}$ & Mean & Median & $t$-stat & $p$-value & $z$-stat & $p$-value \\
\hline ASSETS (\$m) & 174 & 92.20 & 16.70 & 174 & 101.00 & 20.50 & 0.224 & 0.8229 & 0.945 & 0.3445 \\
\hline TECH & 174 & 0.563 & 1 & 174 & 0.460 & 0 & -1.935 & 0.0538 & -1.928 & 0.0539 \\
\hline LIQ & 174 & 0.212 & 0.131 & 174 & 0.335 & 0.241 & 4.304 & 0.0000 & 3.396 & 0.0007 \\
\hline LEV & 174 & 0.291 & 0.196 & 174 & 0.296 & 0.237 & 0.134 & 0.8932 & 0.504 & 0.6142 \\
\hline ATO & 174 & 0.391 & 0.063 & 174 & 0.776 & 0.358 & 3.225 & 0.0014 & 2.947 & 0.0032 \\
\hline ROA & 174 & -0.239 & -0.101 & 174 & -0.083 & 0.007 & 2.075 & 0.0387 & 5.767 & 0.0000 \\
\hline DURN (days) & 174 & 162.9 & 130.5 & 174 & 57.5 & 50 & -11.917 & 0.0000 & -12.780 & 0.0000 \\
\hline RET_OWN & 174 & 0.523 & 0.528 & 174 & 0.595 & 0.628 & 3.221 & 0.0014 & 3.894 & 0.0001 \\
\hline CASH_OUT & 174 & 0.287 & 0 & 174 & 0.259 & 0 & -0.600 & 0.5488 & -0.601 & 0.5480 \\
\hline DAY1_RET & 174 & 0.244 & 0.050 & 174 & 0.235 & 0.100 & -0.117 & 0.9069 & 1.753 & 0.0797 \\
\hline PRCDS (\$m) & 137 & 7.54 & 4.08 & 174 & 41.30 & 10.50 & 3.210 & 0.0015 & 7.454 & 0.0000 \\
\hline UNDERWTR & 137 & 0.314 & 0 & 174 & 0.621 & 1 & 5.625 & 0.0000 & 5.366 & 0.0000 \\
\hline
\end{tabular}


Table 9

Choice between Backdoor Listing and Initial Public Offering: Logit Regression Analysis

\begin{tabular}{|c|c|c|c|c|c|c|c|c|c|}
\hline & \multirow{3}{*}{$\begin{array}{c}\text { Predicted } \\
\text { sign }\end{array}$} & \multirow{2}{*}{\multicolumn{2}{|c|}{ Full sample }} & \multirow{2}{*}{\multicolumn{2}{|c|}{ Re-admissions }} & \multicolumn{4}{|c|}{ Re-admissions \& capital raisings } \\
\hline & & & & & & \multicolumn{2}{|c|}{ All offer types } & \multicolumn{2}{|c|}{ Public offers } \\
\hline & & $(1)$ & (2) & (3) & (4) & $(5)$ & $(6)$ & $(7)$ & $(8)$ \\
\hline \multirow[t]{2}{*}{ CONSTANT } & & $4.310^{* *}$ & -1.795 & $5.543^{* *}$ & $-6.948 * *$ & $-8.780 * *$ & -2.898 & $-13.142 * * *$ & -5.708 \\
\hline & & $(2.33)$ & $(-0.71)$ & $(2.4)$ & $(-1.96)$ & $(-2.17)$ & $(-0.55)$ & $(-2.64)$ & $(-0.91)$ \\
\hline \multirow[t]{2}{*}{ Ln(ASSETS) } & - & $-0.220 * *$ & -0.155 & $-0.267 * *$ & -0.128 & 0.043 & $1.728 * * *$ & 0.1889 & $1.381^{* * *}$ \\
\hline & & $(-2.07)$ & $(-1.33)$ & $(-2.03)$ & $(-0.84)$ & $(0.24)$ & $(4.35)$ & $(0.9)$ & $(3.45)$ \\
\hline \multirow[t]{2}{*}{ TECH } & + & $0.637^{* *}$ & $0.776^{* * *}$ & $0.645^{* *}$ & $0.815^{* *}$ & $1.276^{* * *}$ & $1.429 * * *$ & $1.034 * *$ & $1.225^{* *}$ \\
\hline & & $(2.49)$ & $(2.84)$ & $(2.22)$ & $(2.46)$ & $(3.22)$ & $(2.93)$ & $(2.34)$ & $(2.36)$ \\
\hline \multirow[t]{2}{*}{ LIQ } & - & $-3.172 * * *$ & $-2.790 * * *$ & $-3.679 * * *$ & $-2.917 * * *$ & $-3.591 * * *$ & $-1.812^{*}$ & $-3.671 * * *$ & $-2.435^{* *}$ \\
\hline & & $(-5.65)$ & $(-4.79)$ & $(-5.72)$ & $(-4.18)$ & $(-4.54)$ & $(-1.84)$ & $(-4.19)$ & $(-2.26)$ \\
\hline \multirow[t]{2}{*}{ LEV } & + & $1.426^{*}$ & $1.608^{* *}$ & 0.481 & 0.212 & 0.404 & -0.170 & -0.361 & -0.536 \\
\hline & & (1.92) & $(2.06)$ & $(0.53)$ & $(0.2)$ & $(0.31)$ & $(-0.11)$ & $(-0.25)$ & $(-0.32)$ \\
\hline \multirow[t]{2}{*}{ ATO } & - & $-1.042 * * *$ & $-1.005^{* * *}$ & $-1.034 * * *$ & $-0.915 * * *$ & $-1.380 * * *$ & $-1.293^{* * *}$ & $-1.197 * * *$ & $-1.145^{* *}$ \\
\hline & & $(-4.72)$ & $(-4.35)$ & $(-3.92)$ & $(-3.03)$ & $(-3.41)$ & $(-2.7)$ & $(-2.8)$ & $(-2.28)$ \\
\hline \multirow[t]{2}{*}{ ROA } & - & $-0.839 * * *$ & $-0.777 * *$ & $-0.870 * *$ & $-0.771^{*}$ & $-1.955 * * *$ & $-3.076^{* * *}$ & $-2.039 * * *$ & $-2.713 * * *$ \\
\hline & & $(-2.67)$ & $(-2.49)$ & $(-2.18)$ & $(-1.86)$ & $(-3.43)$ & $(-4.2)$ & $(-3.4)$ & $(-3.62)$ \\
\hline \multirow[t]{2}{*}{$\operatorname{Ln}(\mathrm{DURN})$} & - & & $1.174 * * *$ & & $2.263 * * *$ & $2.230 * * *$ & $2.397 * * *$ & $2.748 * * *$ & $2.628 * * *$ \\
\hline & & & $(4.12)$ & & (5.3) & $(4.8)$ & (4.59) & (4.7) & $(4.29)$ \\
\hline \multirow[t]{2}{*}{ CASH_OUT } & - & & 0.282 & & 0.195 & 0.159 & 0.156 & 0.370 & 0.233 \\
\hline & & & $(0.88)$ & & $(0.48)$ & $(0.34)$ & $(0.25)$ & $(0.69)$ & $(0.35)$ \\
\hline \multirow[t]{2}{*}{ RET_OWN } & - & & $-1.574 * *$ & & $-1.846^{* *}$ & $-3.553 * * *$ & $-7.971 * * *$ & $-4.105 * * *$ & $-7.673 * * *$ \\
\hline & & & $(-2.52)$ & & $(-2.41)$ & $(-3.84)$ & $(-5.4)$ & $(-3.66)$ & $(-4.69)$ \\
\hline \multirow[t]{2}{*}{ DAY1_RET } & - & & 0.153 & & 0.245 & 0.235 & -0.022 & 0.595 & 0.276 \\
\hline & & & $(0.84)$ & & $(1.23)$ & $(0.99)$ & $(-0.07)$ & (1.19) & $(0.52)$ \\
\hline \multirow[t]{2}{*}{ Ln(PRCDS) } & - & & & & & & $-2.089 * * *$ & & $-1.589 * * *$ \\
\hline & & & & & & & $(-5.24)$ & & $(-3.94)$ \\
\hline \multirow[t]{2}{*}{ UNDERWTR } & - & & & & & & -0.465 & & -0.751 \\
\hline & & & & & & & $(-0.94)$ & & $(-1.37)$ \\
\hline Observations & & 348 & 348 & 274 & 274 & 242 & 242 & 200 & 200 \\
\hline Log likelihood & & -203.58 & -188.65 & -154.84 & -130.63 & -99.32 & -71.18 & -77.95 & -60.52 \\
\hline LR Chi-sq & & 75.27 & 105.13 & 70.16 & 118.58 & 136.85 & 193.13 & 121.36 & 156.21 \\
\hline Pseudo $R^{2}$ & & 0.1560 & 0.2179 & 0.1847 & 0.3122 & 0.4079 & 0.5757 & 0.4377 & 0.5634 \\
\hline Correctly classified & & 0.7040 & 0.7126 & 0.7336 & 0.7956 & 0.8099 & 0.8760 & 0.8300 & 0.8750 \\
\hline
\end{tabular}

